\title{
Bridging Serious Games and Participatory Design
}

\author{
Rilla Khaled $^{\mathrm{a}}$, Asimina Vasalou ${ }^{\mathrm{b}}$ \\ ${ }^{a}$ Institute of Digital Games, University of Malta, Msida, Malta \\ ${ }^{b}$ London Knowledge Lab, Institute of Education, 23-29 Emerald Street, London, \\ United Kingdom
}

\begin{abstract}
Participatory design (PD) has become widely popular within the interaction design community, but to date has had little influence within serious game design processes. We argue that serious game design complicates the notion of involving users as co-designers, as serious game designers must be fluent with both domain content and game design. In this paper, we share our experiences of using PD during the design process of a serious game. We present observations stemming from attempts to apply the existing PD methods of brainstorming and storyboarding. Reflecting on the shortcomings of these methods, we go on to propose a novel PD method that leverages two fundamental qualities of serious games - domain expertise and procedurality - to scaffold players' existing knowledge and make co-design of serious games an attainable goal.
\end{abstract}

Keywords: participatory design, serious games, children, procedural literacy, conflict resolution education

\section{Introduction}

Serious games are chameleon technologies. As games, they are expected to entertain, motivate and engage. As learning technologies, they must appropriately embody domain knowledge and sound pedagogical principles. Depending on their context of use, they need to integrate with existing social and technological structures and dynamics. The multiplicity of design needs

Email addresses: rilla.khaled@um.edu.mt (Rilla Khaled), a.vasalou@ioe.ac.uk (Asimina Vasalou) 
serious games must fulfil ramps up the difficulty of designing them, especially contrasted against conventional entertainment-oriented games [22].

Serious game design has inherited many of its design traditions from entertainment-oriented game design. In typical entertainment-oriented game design, the player is rarely consulted in early stage game design, and often involved only when a playable version of a game exists $[6,18]$. Accordingly, in well-known approaches and best practice for serious game design, the player's involvement during the conceptual design stage is minimal [4, 22]. Despite this historical focus on designer agency, increasingly, design processes for games are changing. Entertainment game designers have begun investigating ways of crafting experiences in collaboration with players, e.g. [8, 18], while growing numbers of serious game designers have explored ways to involve players in the design process as a way to mitigate their knowledge gaps, e.g. $[3,10,19,20]$.

These changing practices come at a time when technology designers are calling for the increased use of co-design with end users [14]. Those who advocate participatory approaches to design argue that they increase the public's engagement with research, facilitate learning and change, ensure that technologies are aligned to people's needs and remove designer subjectivity $[11,13,21]$. Participatory design (PD) is as much a moral proposition about how to design as it is a pragmatic one about ensuring that needs are met through design.

In taking a co-design focused, participatory approach to serious game design, the lack of a deep tradition of participatory game design and, more fundamentally, some of the challenges of applying PD within serious game design mean that several basic issues remain unresolved. In the specific case of serious games targeted at young audiences, how should we incorporate children's taste in games when working in highly specific domains? What should we do when the end users themselves don't understand the domain? How should we proceed when the game design ideas provided by children are inappropriate? As design visionaries continue to propagate the designer's changing role from a translator to facilitator and the end user's role from informant to co-designer $[13,14]$, serious game designers are faced with the challenge of incorporating and leveraging these philosophies such that players can benefit from the opportunities that they offer, in light of the challenges they may introduce. 


\section{PD and Serious Games Design}

PD emerged in Scandinavia in the 1970s, in response to concerns from workers and union members that the introduction of IT in the workplace would lead to reduced influence in the workplace, disempowerment, and a loss of jobs [11]. In recent years, PD has become commonplace within mainstream design practice and its application has widely diversified [21]. Despite its uptake within the wider interaction design community, PD within serious game design practice has been limited. While efforts have been made towards incorporating users in the design process, user participation has often taken constrained forms, for example, to provide feedback to ideas that designers have developed [19] or to provide inspirational input to designers [3]. Efforts to involve users as co-designers have often proven difficult. During the design of a game for developing social skills, Tan et al. asked children to play an early game prototype and to create storyboards of potential game narratives. While children provided a wealth of information that was used to improve the game, they often proposed ideas well beyond the learning objectives of the game, including violent and competitive mechanics that conflicted with the very purpose of the game being designed [19]. Similarly, Mazzone et al. involved young people in the design of a game for improving teenagers' emotional intelligence. When they asked participants to design actions in relation to game rewards, the output consisted of unfocused ideas. This led the authors to conclude that the task required too high a level of abstraction for participants to meaningfully contribute [10].

The difficulties of involving users in serious game design become more understandable when taking into consideration a typical serious game design process. In the Design, Play, Experience model of serious game design, Winn characterises successful serious game design as a synthesis of pedagogical theory, domain content, and game design. As learning objectives are central to most serious games, Winn proposes that designers begin by focusing on domain content and pedagogical approaches, as these are most inflexible. Next, designers should consider settings, characters, and narratives that make sense in light of the learning focus. Designers can then move to establishing mechanics that make the domain content playable. Finally, designers should consider user interface aspects [22]. However, as the serious games community generally agrees that serious games should be endogenous (where context is intertwined with content) rather than exogenous (where context and content are independent) [4], designers need to be able to tightly 
couple domain content to game mechanics. That is, those contributing to design need to be knowledgeable of both. As a result, two significant participation barriers for end users in serious game design are domain content familiarity and game design literacy. A similar barrier emerges when examining the application of PD in the context of educational technologies, which are conceptually related to serious games. Concerning the design of learning environments, Scaife et al. propose that children be involved as informants rather than co-designers, given that children frequently lack knowledge of the domain area, thus limiting their abilities to propose relevant ideas [15].

In summary, the serious game design process complicates the notion of involving users as co-designers. Serious game designers must be fluent with both domain content and game design. Users, conversely, may lack one or both of these forms of knowledge. At the same time, PD approaches to serious game design could provide significant value for users, for example, by strengthening their domain knowledge as a result of actively contributing to the design process. We thus argue that it is imperative to continue building our understanding of how PD methods can apply to serious games, such that the aspirations of PD can be achieved through serious game design processes. The present paper fits with this objective. We detail the use of $\mathrm{PD}$ across the design cycle of a serious game intended to teach primary school children conflict resolution skills. In a first case study, we examine the ability of existing methods, namely brainstorming and storyboarding, to support children's ideation. Building from lessons learned during the use of these methods, we then present a second case study that introduces a novel method for involving participants in serious game design. Before presenting the case studies, we provide the background and rationale of our project.

\section{Village Voices: A Serious Game for Teaching Conflict Resolu- tion Skills}

Conflicts are inevitable episodes occurring in all stages and spheres of life, and mastery of conflict resolution skills plays a part in determining how well an individual can integrate into society [5]. As such, conflict education is seen as important to introduce at an early age. This is expressed in educational policies, both in England and the United States [5]. Given the importance of conflict education for social and emotional learning, we set out to develop a structured and engaging serious game for use in schools that would facilitate learning about conflict resolution. 
One approach that has been strongly influential in conflict education is the use of drama-based methods and workshops. Through role-play, children are encouraged to try out different conflict responses in a supervised environment. As such, we decided to design an open-world multi-player game that would similarly enable a broad range of behaviours. In particular, our work was informed by Bodine and Crawford's influential conflict education model [2]. One principle in particular, teaching children how to separate the people from the problem, became the focus of our project. This principle assists in disambiguating children's general relationship difficulties and the deeper factors exacerbating the conflict with the surface reason for conflict. Three types of relationship difficulties are emphasized: perceptual difficulties such as how people may see an issue from different perspectives, emotional difficulties, i.e. acknowledging that strong emotions distort an issue and make it seem more serious than it would otherwise appear, and communication difficulties marked by problems with sharing one or more parties' perspectives or feelings on an issue.

Our serious game, Village Voices, is a four-player game set in a fictional village during pre-industrialisation times. It is designed to be played in a classroom under teacher supervision. When the game begins, each player is assigned one of four characters to play: the blacksmith, the innkeeper, the alchemist, or the carpenter. As part of daily life in the village, players undertake various actions related to maintenance of their characters' livelihoods, and also complete quests. For example, the alchemist tends to his crop of magic mushrooms, keeps an eye on his health, and might be building a barrier wall to keep wolves out of the village. At the same time, all of the characters are interdependent, thus situations inevitably arise that trigger conflicts or exacerbate existing ones. For example, in order to complete the wall, the alchemist may need to obtain an item from the innkeeper, who he is not on good terms with due to a previous theft incident. While players may initially be faced with simple quests involving no trades or only one trade with other characters, more difficult quests involve trades with all three of the other characters. Given that players have the ability to perform actions that can lead to conflict including theft, property damage, spreading rumours, and not sharing collective resources such as food, completing multi-player quests can rapidly become difficult.

Many digital learning games adopt an explicitly didactic approach to conveying domain knowledge. But what constitutes constructive resolution of conflict can be situationally and culturally dependent. Instead of explicitly 


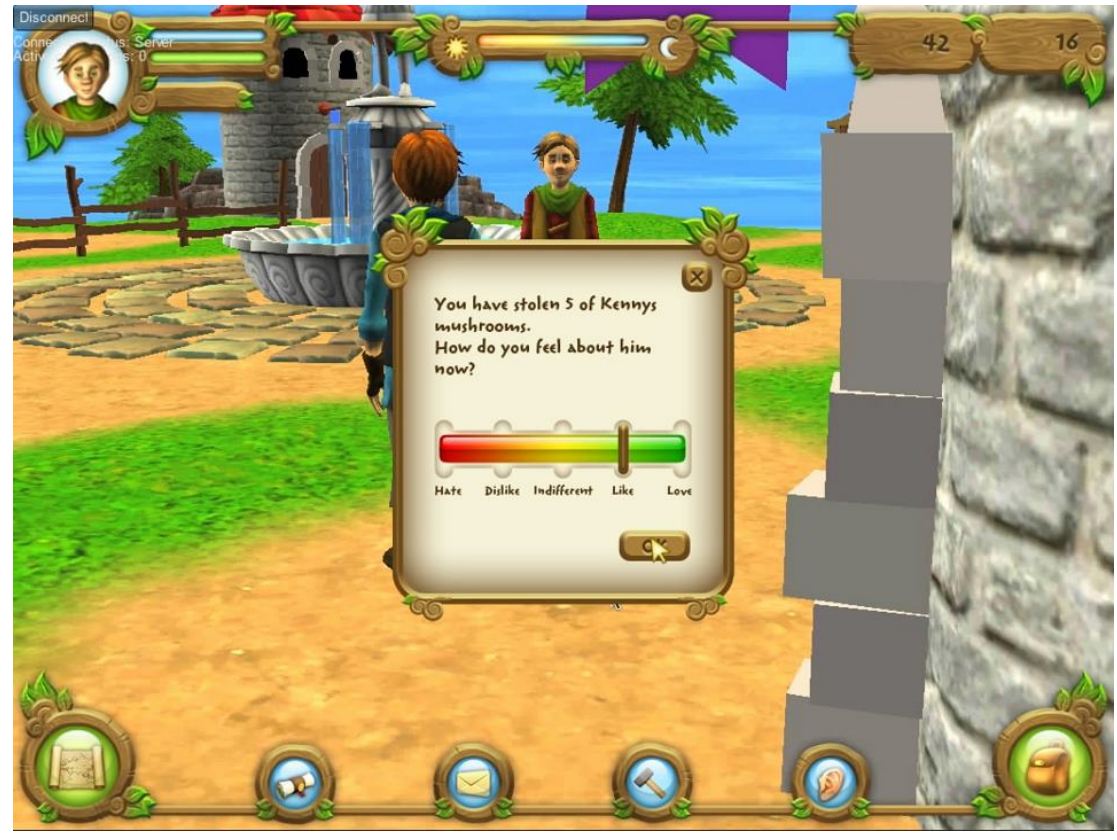

Figure 1: Reporting on feelings in Village Voices.

instructing players how to resolve particular conflicts, Village Voices creates situations in which players are pushed into conflicts with one another. Players therefore experience conflict from a first-person perspective, and must use the affordances of the game, along with offline conversation and negotiation, to establish and enact conflict management strategies. Figure 1 presents a screenshot of Village Voices, during which one player has been requested to report her post-theft feelings towards another player.

\section{Case Study 1: Germinal and Organisational Methods}

In our first case study, we present experiences of using two existing PD methods during an early stage of game design for the purpose of generating game narratives and mechanics. In particular, we focus on how the two methods supported the generation of effective ideas.

\subsection{Participants}

The workshop took place at a dedicated lab space at the innovation centre in the city of Bath (South West of England). The researchers had established 
connections with the Black families education centre early on in the project. The centre was interested in contributing to our project given their focus on inter-racial conflict. Through the centre, three boys aged 10 were invited to take part. The participants were familiar with each other as they all attended events at the centre on a weekly basis. All of the children reported playing games regularly.

\subsection{Procedure and Method}

The workshop was held early in the design process. As a result, the game design concept presented in Section 3 had not been yet developed. The aim of the workshop was two-fold: to obtain conflict-focused narratives to feature in the game, as well as the game mechanics that would realise them.

In $\mathrm{PD}$, designers and users navigate the problem space through the use of boundary objects, including low fidelity prototypes, role-playing games, and sketches $[11,14,21]$. During early design stages, the boundary objects used are typically open-ended and ambiguous, thus inviting stakeholders to imbue them with meaning potentially unforeseen by designers [1]. In line with this view, we loosely defined the scope of our game, as we hoped to keep the design space sufficiently flexible such as to invite children's interpretations.

Our first activity, brainstorming, was based on a germinal approach intended to create new ideas from scratch [16]. We introduced 'games for conflict education' as a boundary object. Through a series of examples, we explained to children that conflict varied in its intensity, that people responded in different ways to conflict with responses ranging from collaborative to aggressive, and that conflict had a longer-term impact on people's relationships. These definitions were reinforced by asking children to reflect on their own experiences with peer conflict. After introducing key concepts to conflict, we moved on to brainstorming on specific game elements: we asked the children to detail what the goals of a conflict resolution game should be, how players should be allowed to progress in such a game, what actions the game should make available and which actions should be rewarded.

Next, we introduced participants to our second activity, storyboarding, based on an organisational approach to elicit causal inferences between potential game characters' actions and action consequences [16]. Our boundary object was a 'conflict narrative', which we defined to children as an event that triggers conflicts and provokes responses between the parties involved. Children were provided with the comic book tool, Pixton. Pixton allows users to choose a variety of environments and characters. Characters can 
be customised through the assignment of postures, emotion expressions and dialogue. After acquainting the children with Pixton's basic functionality, each of them used it to storyboard a conflict narrative. At the end of the session, children were given printouts of their comics.

The workshop lasted four hours in total including an initial warm up phase during which children created game characters with play dough, and regular breaks. The workshop was facilitated by a design researcher and a developmental psychologist. Children's interactions and ideas were video recorded, and notes were taken by one of the researchers.

\subsection{Analysis}

We conducted thematic analysis on the data collected during the workshop focusing on how characteristics of each method influenced idea effectiveness. In previous work, Shah et al. have proposed four metrics for establishing idea effectiveness for engineering design. Novelty captures how new the idea is compared to other ideas; variety of ideas measures differences between ideas proposed, with more ideas indicating a widening of the design space; quality expresses how feasible the idea is to implement and how well it meets the initial specification; quantity measures the number of ideas produced [17]. In the context of product design, O'Quin and Besemer have proposed three dimensions for capturing creativity [12]. Their model has been applied to assess ideas, processes and products. Two of their three dimensions concur with Shah et al.'s metrics. These are: novelty in the concept or process produced and resolution. Resolution focuses on one aspect of quality, whether the idea is fit for the purpose it was meant to fulfil. The third dimension proposed by O'Quin and Besemer is style and encapsulates the presentation or aesthetics of the technology, once a product has been created. Our analysis was focused on the dimensions that were shared between the two models: novelty and quality.

\subsection{Results and Discussion}

During the brainstorming activity, the children's ideas were largely grounded in game concepts they had encountered before. None of the ideas were novel when compared to each other, nor when they were placed in the broader context of game design. Indeed, some of the ideas proposed could well have applied to any game, regardless of whether or not there was an educational objective involved. One such example is customisation, with participants voicing desires to customise not only their avatars, but also the game world. 
One boy drew a parallel with a game he regularly played: "in Miniclip there's this thing where you can, like, make your own person". Even though the nature of the features proposed would not have disrupted the core learning objective of the game, they did not add any particular value from the context of conflict education. Implementing them would have taken away resources from more educationally relevant features.

Ideas concerning game mechanics directly related to conflict education seemed to be particularly problematic for the participants. While the children were literate with game tropes, they were unable to meaningfully connect them to conflict resolution, often leaving their ideas highly underspecified. For instance, while in-game currency was repeatedly mentioned as a reward for achieving game objectives, the children were less clear as to what these objectives might be. In the words of one of our participants: "You have to unlock stuff and you get money". Another suggested that a "Health bar could go down if you make bad decisions", but stopped short of defining what a bad decision might be. In yet another case, a mechanic from an action game was proposed as a conflict resolution response, but the participant's emphasis seemed to be the creation of thrilling actions rather than the significance of the action in the context of conflict: "When you're cycling to school, there could be a kind of gang... cycle through objects while they're chasing you".

During the storyboarding activity, children used the tool Pixton to create conflict triggers, responses and outcomes between conflict participants. This activity elicited prototypical examples of conflict. Specifically, two participants created bullying incidents that occurred at school, while a third one represented a property dispute over a basketball. They all proposed aggressive and violent reactions between the conflict parties, along with withdrawal responses. Two children developed scenarios in which a teacher mandated a fair resolution between the conflict parties. Figure 2 presents an example storyboard. In ascertaining the quality of the ideas generated, we observed that children's identification of conflict triggers was limited to intense episodes of conflict, even though previous research has shown that the most pervasive forms of conflict are the least severe [20]. The responses children proposed for conflict were also limited, and in fact deemed suboptimal in contemporary conflict resolution management programmes [2]. Given children's narrow and overly antagonistic understanding of conflict, we were unable to use their narratives as a basis for game design.

Neither of the activities involved in our first workshop yielded particularly 

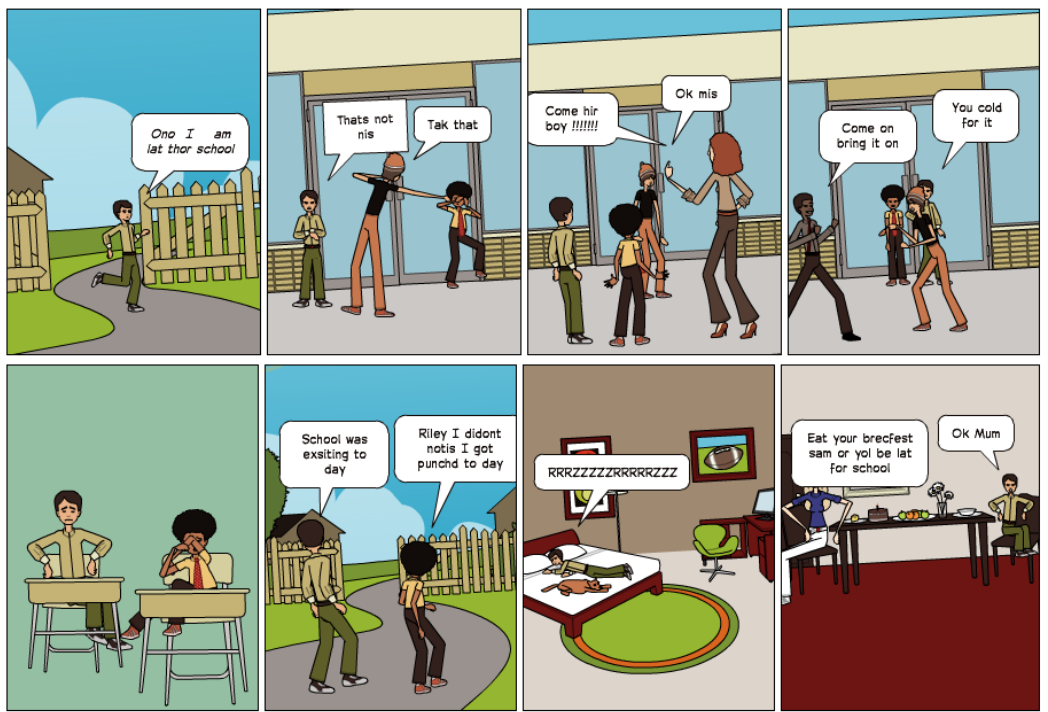

Figure 2: Example storyboard displaying conflict, responses and outcomes.

promising outputs. The limited domain knowledge of the children became a barrier when it came to developing ideas that fulfilled the initial specification, i.e. to teach conflict resolution skills. This barrier became more severe as a result of the overly open-ended qualities of our boundary objects, which did not scaffold children's idea generation to surmount their lack of knowledge. As a consequence, children fell back on what they did have knowledge of: familiar game mechanics and design tropes. Despite the limitations of the activities, however, they enabled us to observe children's high game literacy and enthusiasm for games. Children were swift to imagine and articulate complex interactions between game components such as goals, rewards, actions and progress.

\section{Case Study 2: Transformational Methods for PD}

In our second case study, we present a novel PD method that we developed for use during later stages of game design. As with the methods used in the first case study, our intention was to elicit narratives and mechanics for the game from participants. Again, we focus on how attributes of our method helped support the generation of effective ideas.

We point out that between the workshops described in the first case study and the ones that we went on to conduct for the second case study, 
our design concept had matured significantly. Given the paucity of usable concepts generated by end users during our brainstorming and storyboarding workshop, and due to time constraints enforced by our project timeframe, we proceeded in developing an initial barebones multiplayer game system. The multiplayer aspect of the game was informed by the conflict resolution literature, Bodine and Crawford's approach to conflict resolution education [2], as well as our project commitment to computationally model conflict between players [7]. The basic mechanics of the game were inspired both by Bodine and Crawford's approach as well as passive forms of input obtained through ethnographies conducted at local schools [20]. For example, one category of conicts observed at schools, property disputes, inspired a stealing mechanic, while friendship disputes inspired a rumour spreading mechanic. In this way, the barebones game system, an early version of Village Voices, was capable of supporting game mechanics related to the most prevalent causes and triggers of conflicts amongst the target age group according to our research. This barebones game system served as the boundary object of concern for the second case study.

\subsection{Participants}

Two workshops were organised with thirteen children in total. The first took place at a community centre in the town of Leamington Spa (Midlands of England). Researchers advertised the workshop through flyers posted at a number of locations throughout the town including a community centre, the main leisure centre and several toy stores. Ten children (nine boys) between the ages of 9-11 attended. Some of the children knew each other from local schools and four of the children were siblings. All of the children played games on a regular basis. The second workshop was organised at another community centre, also in the town of Leamington Spa. It was advertised through a local school that had recently participated in conflict peer mediation training. Three girls aged 10 who had received the training attended. The girls were friends at school. Unlike participants from the other workshops, they only played games occasionally.

\subsection{Procedure and Method}

The first workshop lasted four hours. Children were divided into two teams of five. Five researchers were present: a game designer, a design researcher who led the facilitation of the two groups, and three note takers. The second workshop lasted three hours and followed the same procedure as 
that of the first workshop. Two design researchers were present, with one acting as a facilitator and the other as a note taker. In both workshops, parental and child consent were obtained prior to any workshop activity. During the workshops, video recordings were made for analysis purposes. Our analysis followed the same protocol (focusing on idea novelty and quality) as in case study one.

In both workshops, the barebones game system served as a focal point of attention. We had previously observed a lack of domain knowledge as being a significant barrier for the elicitation of novel and quality ideas, thus our intention was to remove the burden of establishing pedagogically appropriate concepts from scratch, while capitalising on children's game literacy. As such, we devised an activity based on a transformational approach in which ideas were generated and developed based on the barebones game system [16]. Our system provided children with pedagogically-appropriate ideation scaffolding, as it already incorporated conflict resolution training best practice. It was open to the incorporation of newly invented mechanics, provided the new additions fit with its existing system components. We guided the children through a series of steps targeted at enabling them to unpack the barebones game system, make additions to constituent parts, and then recombine the newly modified parts back into the whole design concept. These steps are described next.

Children were first presented with a short video and an explanation of the Village Voices concept. After we ensured that they had grasped the basic rationale of the game, we incrementally introduced game design tasks.

Characters and trades. Three game characters were introduced: the alchemist, the innkeeper and the blacksmith. By introducing multiple characters early on, we hoped to prompt children to view conflict as an interpersonal issue where each party might have interests and positions. Each team was given three Lego mini figurines representing each character, and asked to brainstorm potential trades between them. While children brainstormed, each facilitator drew a network of trades and connections between the three characters. Following the definition of trades, children were asked to define rules to govern trades and used art materials to design physical locations for the game characters.

Motivations and meters. After establishing mechanics and features around trading, children were asked to develop an engaging game world by defining 
quests and fun activities for the characters. In addition, we presented them with three meters we had developed for the game: livelihood, health and liking (concerning other players). We had already determined that our game would not explicitly state whether resolution approaches were correct or incorrect; instead we opted to have players' relationship statuses with one another serve as feedback as to whether a resolution approach was perceived as acceptable. We asked the children to explain how the meters would be affected during trades and newly introduced quests. We introduced Rory's Story Cube dice as an optional additional prompt in case children needed help generating ideas. Each side of the dice presents an icon, and dice users must tell a story that brings the icons together.

Conflicts and resolution strategies. After exploring relationships between game events and meters, we shifted our focus to translating learning objectives into game mechanics. Children were asked to design potential sources and triggers of conflict between characters, as well as actions that game characters could employ as conflict responses. We prompted children to propose both competitive and collaborative responses, as well as constructive and destructive responses. Additionally, we presented two conflict resolution-related game features we had developed. The first one was the guru status indicator that a player would obtain on demonstrating a degree of expertise in conflict resolution. Both children who had built up their expertise through game progression and teachers would be able to occupy this role. The second was the concept of a town council that would convene to give advice each time a conflict occurred. Players would be required to participate in the council and contribute towards discussions of how to resolve the conflict in question. Children critiqued these features and further developed them, and also established new supporting mechanics. Figure 3 shows some ideas regarding game mechanics for the guru and character trades between the alchemist and innkeeper.

\subsection{Results and Discussion}

Children proposed numerous ideas to address the game design challenges posed. While idea quantity was not a focus in our analysis, children's level of engagement within the workshop was exemplified through their desire to stretch their imagination beyond what was asked of them. For example, in two out of the three groups, children proposed new characters, such as a sheriff and a farmer. During the workshops, two modes of collaboration naturally 

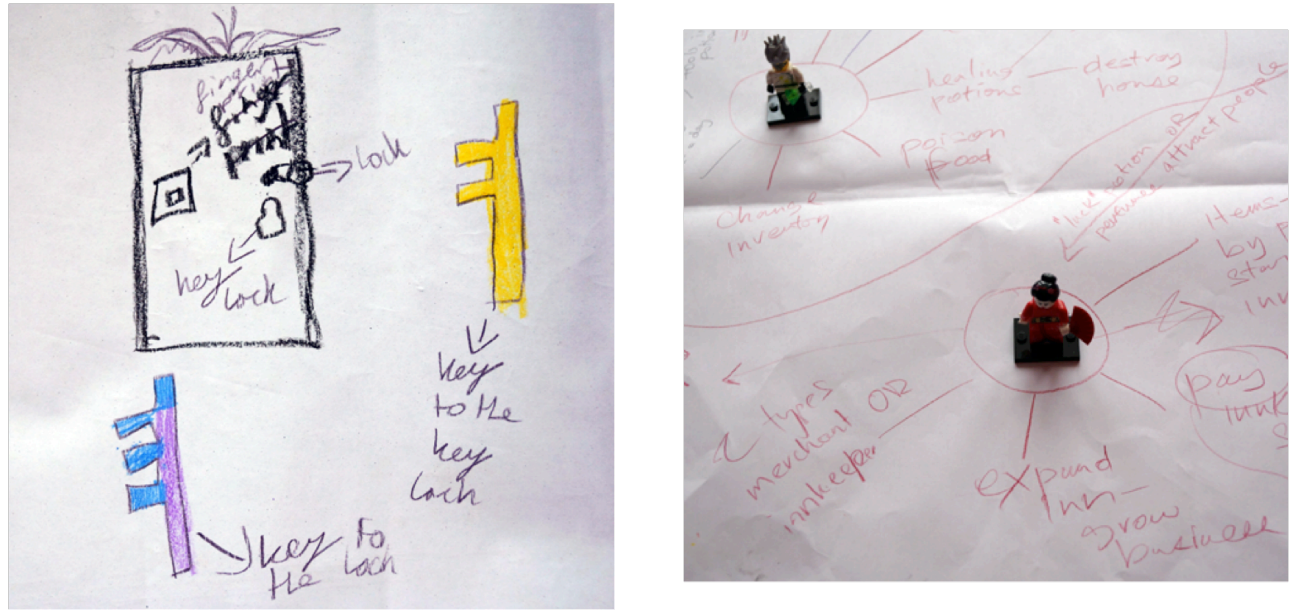

Figure 3: Game mechanics (Guru) and character trades (Alchemist and Innkeeper)

emerged. In the first mode, children freely proposed ideas in response to game components, which the facilitator documented and synthesised on a shared canvas of paper. This brainstorming was often followed by focused activities where children would further develop a particular idea using low-fidelity art materials. The second mode of collaboration was characterised by strong consensus between children regarding particular game design decisions. For example, all of the children agreed that rules regarding fair trade needed to be established by the players. Additionally, one of the groups was strongly opposed to our idea of the teacher occupying the guru role out of concern that it would defeat the purpose of the game. As one of the participants explained, "Teachers are strict and the game will not be fun".

Children offered many novel ideas to extend the narrative of the game. Importantly, these ideas remained within the boundaries of the Village Voices concept and were thus feasible to implement. For example, in being told that the game would be played within the classroom, children proposed that students grouped together in a game session visit other students' 'villages'. They suggested that successful game progression might be communicated by the village transforming into a city. Unsurprisingly, the alchemist role prompted many design interpretations, with children proposing potions for healing, harmful spells, or granting special powers.

Children also managed to propose novel ideas in relation to the overall learning objectives of the game, although the quality of the ideas varied. In a few cases, children took inspiration from the learning objectives, while 
not strictly observing what the objectives entailed. For example, one team suggested that a non-player sheriff character could punish those involved in conflict, thus avoiding the need for players to manage conflicts themselves. Another team proposed that those with guru status could help players with a low welfare status, without elaborating on what the players would learn through this process. They recommended the addition of a 'bank' to give loans to those who had been uncooperative with other villagers, thus providing players with the option to avoid learning about conflict resolution.

Other ideas, however, were both feasible and suitable. In connection with what kinds of conflicts could arise between characters, children proposed that the alchemist might accidentally make faulty potions for other characters that would potentially lead to those characters becoming ill. The children agreed that there should be negative consequences for the alchemist in this case, but that the consequences should be lighter than those resulting from the situation in which the alchemist had intentionally provided other characters with a faulty potion. This illustrated a degree of reflection into the importance of intent during conflict. Some children asserted the status of the game as a tool for conflict education. They argued that even though players might be aggressive within the game, a condition of success within the game would be to resolve the conflict. Extending the concept of the town council, they suggested that in cases where players were unable or unwilling to resolve the conflict through the council, they would require a lawyer, resulting in a reduction of livelihood, and thus introducing incentives to engage in conflict resolution.

As a boundary object, the barebones game system scaffolded the drawing of relationships between game system elements and conflict resolution concepts and invited the addition of new, supporting concepts. Indeed, both workshops yielded output that was novel and of quality. However, the different expertise of the participants across the two workshops led to differences in the types and strengths of ideas produced. As children from the first workshop had a high degree of game literacy, they readily made sense of systems of relationships and were able to think procedurally, a mode of perception natively exercised by playing games [9]. As a result, they were adept at proposing complex interdependencies between characters, meters, mechanics, and game subsystems. While some of their ideas did not align with our learning objectives, many of the ideas did, supporting the notion that the incomplete barebones game system successfully embedded domain expertise, while also inviting relevant ideation. Moreover, while articulating how the 
larger ecosystem of game behaviours would work, we observed that children initially naïve to the domain of conflict resolution were now reflecting on what fair conflict resolution should entail.

In contrast, children from the second workshop were less familiar with games, but had all undertaken peer mediation training. The ideas they proposed in relation to the game's learning objectives were more consistent with our understanding of the domain, drew directly from peer mediation expertise and represented target audience best practice. Nonetheless, they struggled to contribute ideas not directly related to conflict, and needed to use the Rory's Story Cube dice as additional support for brainstorming. The differing strengths of workshop participants in relation to our method highlights a literacy issue. While ideation around the basic game system was easier for those with high game literacy, ideation around learning objectives was easier for those with prior training in peer mediation. In traditional PD, being from the target user group constitutes a form of expertise that qualifies participation. Our findings suggest, however, that participants who are already literate with qualities of the boundary object - in our case, games and domain knowledge - are more likely to produce effective ideas in relation to it.

\section{Conclusion}

PD introduces new opportunities for designers and players of serious games. Informed by experiences of using existing PD methods for game design ideation, we developed a novel PD method to scaffold ideation that supported and represented core concerns of serious games, namely, domain expertise and procedurality. We conclude with three key considerations for involving children in PD for serious games.

Children were most effectively able to participate as co-designers during middle stages of the game design process. In an early design stage, before we had settled on which domain content and pedagogical theory to communicate in our game, the boundary objects we used were open-ended, and failed to provide enough theoretical scaffolding to assist participants in establishing specific and relevant ideas. In contrast, the more specific boundary object used in later workshops elicited novel ideas that supported the educational objectives of the game. Qualities of boundary objects used in PD for serious games should be considered in light of the role they play in supporting and eliciting ideation. During later stages of the design cycle, designers are better 
positioned to develop boundary objects that embody the necessary theoretical underpinnings and scaffolds to support children in generating effective ideas.

Moreover, to maximise the chances of successful ideation from participants, it is necessary to devise boundary objects that relate to their expertise. During the brainstorming and storyboarding activities, the boundary objects provided did not deeply resonate with the expertise of the children. In contrast, during the transformational game activity, participants from the first workshop were able to exercise their procedural literacy, while participants from the second workshop were able to draw on their conflict mediation training. Of course, in design situations in which there are longitudinal relationships between participants and the design team, it is possible to train participants such that they gradually acquire the expertise needed to contribute as co-designers. However, this can be a costly investment and, as in our case, assumes a degree of access to participants that many design teams lack [3].

Finally, many children today have grown up with ubiquitous access to games, and correspondingly, have a high degree of game literacy. For participants who were familiar with games, the transformational method usefully leveraged their game literacy. That is, they were able to harness their abilities to think procedurally as a way to access and understand new domain content, namely, conflict resolution, and to be able to systematically consider conflict cause-and-effect relationships and action-consequence pairings. Given that a potential benefit of involving children in PD concerns empowerment by exposing them to domain content, drawing on participants' procedural literacy as a means to facilitate understanding is a powerful approach that we believe has extension to many domains.

\section{Acknowledgements}

We thank Gordon Ingram, Anastasia Pappa, Richard Joiner, and the enthusiastic participants of all of the workshops. This work has been supported by the EU FP7 ICT projects SIREN (project number: 258453) and ILearnRW (project number: 318803).

\section{References}

[1] Barley, W. C., Leonardi, P. M., \& Bailey, D. E. (2012). Engineering objects for collaboration: Strategies of ambiguity and clarity at knowledge 
boundaries. Human Communication Research, 38, 280-308.

[2] Bodine, R., \& Crawford, D. (1998). The Handbook of Conflict Resolution Education: A Guide to Building Quality Programs in Schools. JosseyBass Inc. Publishers.

[3] Danielsson, K., \& Wiberg, C. (2006). Participatory design of learning media: Designing educational computer games with and for teenagers. Interactive Technology \&3 Smart Education, 3, 275-291.

[4] Isbister, K., Flanagan, M., \& Hash, C. (2010). Designing games for learning: insights from conversations with designers. In Proceedings of the 28th international conference on Human factors in computing systems CHI '10 (pp. 2041-2044). New York, NY, USA: ACM.

[5] Jones, T. S. (2004). Conflict resolution education: The field, the findings, and the future. Conflict Resolution Quarterly, 22, 233-267.

[6] Khaled, R. (2012). Muse-based game design. In Proceedings of the Designing Interactive Systems Conference DIS '12 (pp. 721-730). New York, NY, USA: ACM.

[7] Khaled, R., \& Ingram, G. (2012). Tales from the front lines of a largescale serious game project. In $C H I$ (pp. 69-78).

[8] Lange-Nielsen, F., Lafont, X. V., Cassar, B., \& Khaled, R. (2012). Involving players earlier in the game design process using cultural probes. In Proceedings of the 4th International Conference on Fun and Games FnG '12 (pp. 45-54). New York, NY, USA: ACM.

[9] Mateas, M. (2008). Beyond fun. chapter Procedural Literacy: Educating the New Media Practitioner. (pp. 67-83). Pittsburgh, PA, USA: ETC Press.

[10] Mazzone, E., Read, J. C., \& Beale, R. (2008). Design with and for disaffected teenagers. In Proceedings of the 5th Nordic Conference on Human-computer Interaction: Building Bridges NordiCHI '08 (pp. 290297). New York, NY, USA: ACM.

[11] Muller, M. J. (2003). The human-computer interaction handbook. chapter Participatory design: the third space in HCI. (pp. 1051-1068). Hillsdale, NJ, USA: L. Erlbaum Associates Inc. 
[12] O'Quin, K., \& Besemer, S. (2006). Using the creative product semantic scale as a metric for results-oriented business. Creativity and Innovtation Management, 15, 34-44.

[13] Rogers, Y., \& Marsden, G. (2013). Does he take sugar?: moving beyond the rhetoric of compassion. Interactions, 20, 48-57.

[14] Sanders, E. B., \& Stappers, P. J. (2008). Co-creation and the new landscapes of design. CoDesign: International Journal of CoCreation in Design and the Arts, 4, 5-18.

[15] Scaife, M., Rogers, Y., Aldrich, F., \& Davies, M. (1997). Designing for or designing with? informant design for interactive learning environments. In Proceedings of the ACM SIGCHI Conference on Human Factors in Computing Systems CHI '97 (pp. 343-350). New York, NY, USA: ACM.

[16] Shah, J., Kulkarni, S., \& Vargas-Hernandez, N. (2000). Guidelines for experimental evaluation of guidelines for experimental evaluation of idea generation methods in conceptual design. Journal of Mechanical Design, 122, 377-384.

[17] Shah, J. J., Smith, S. M., \& Vargas-Hernandez, N. (2003). Metrics for measuring ideation effectiveness. Design Studies, 24, $111-134$.

[18] Sotamaa, O., Ermi, L., Jäppinen, A., Laukkanen, T., Mäyrä, F., \& Nummela, J. (2005). The Role of Players in Game Design: A Methodological Perspective. In Proceedings of the 6th DAC Conference (pp. 34 - 42). Copenhagen.

[19] Tan, J. L., Goh, D. H.-L., Ang, R. P., \& Huan, V. S. (2011). Childcentered interaction in the design of a game for social skills intervention. Comput. Entertain., 9, 2:1-2:17.

[20] Vasalou, A., Ingram, G., \& Khaled, R. (2012). User-centered research in the early stages of a learning game. In Proceedings of the Designing Interactive Systems Conference DIS '12 (pp. 116-125). New York, NY, USA: ACM.

[21] Vines, J., Clarke, R., Wright, P., McCarthy, J., \& Olivier, P. (2013). Configuring participation: On how we involve people in design. In Proceedings of the SIGCHI Conference on Human Factors in Computing Systems CHI '13 (pp. 429-438). New York, NY, USA: ACM. 
[22] Winn, B. (2008). The design, play, and experience framework. In Handbook of Research on Effective Electronic Gaming in Education (pp. 1010 - 1024). Hershey, Philadelphia: IGI Global Publication. 